\title{
An Effective Modelling Approach to Support Probabilistic Flood Forecasting in Coastal Cities-Case Study: Can Tho, Mekong Delta, Vietnam
}

\author{
Hieu Ngo ${ }^{1, *}$, Assela Pathirana ${ }^{1}$ (D), Chris Zevenbergen ${ }^{1,2}$ and Roshanka Ranasinghe ${ }^{1,3,4}$ \\ 1 Department of Water Science and Engineering, IHE Delft Institute for Water Education, P.O. Box 3015, \\ 2601 DA Delft, The Netherlands; a.pathirana@un-ihe.org (A.P.); c.zevenbergen@un-ihe.org (C.Z.); \\ r.ranasinghe@un-ihe.org (R.R.) \\ 2 Department of Hydraulic Engineering, Faculty of Civil Engineering and Geosciences, Delft University of \\ Technology, P.O. Box 5048, 2628 CN Delft, The Netherlands \\ 3 Department of Water Engineering and Management, University of Twente, P.O. Box 217, \\ 7500 AE Enschede, The Netherlands \\ 4 Harbour, Coastal and Offshore Engineering, Deltares, P.O. Box 177, 2600 MH Delft, The Netherlands \\ * Correspondence: h.ngo@un-ihe.org; Tel.: +31-068-769-9329
}

Received: 12 March 2018; Accepted: 4 May 2018; Published: 11 May 2018

\begin{abstract}
Probabilistic flood forecasting requires flood models that are simple and fast. Many of the modelling applications in the literature tend to be complex and slow, making them unsuitable for probabilistic applications which require thousands of individual simulations. This article focusses on the development of such a modelling approach to support probabilistic assessment of flood hazards, while accounting for forcing and system uncertainty. Here, we demonstrate the feasibility of using the open-source SWMM (Storm Water Management Model), focussing on Can Tho city, Mekong Delta, Vietnam. SWMM is a dynamic rainfall-runoff simulation model which is generally used for single event or long-term (continuous) simulation of runoff quantity and quality and its application for probabilistic riverflow modelling is atypical. In this study, a detailed SWMM model of the entire Mekong Delta was built based on an existing ISIS model containing 575 nodes and 592 links of the same study area. The detailed SWMM model was then systematically reduced by strategically removing nodes and links to eventually arrive at a level of detail that provides sufficiently accurate predictions of water levels for Can Tho for the purpose of simulating urban flooding, which is the target diagnostic of this study. After a comprehensive assessment (based on trials with the varying levels of complexity), a much reduced SWMM model comprising 37 nodes and 40 links was determined to be able to provide a sufficiently accurate result while being fast enough to support probabilistic future flood forecasting and, further, to support flood risk reduction management.
\end{abstract}

Keywords: coastal cities; SWMM; simplified model; Mekong Delta; Can Tho city

\section{Introduction}

Coastal cities are among the most urbanised and populated areas of the world [1-5]. Small and Nicholls [1] estimated that, in 1990, 23\% of the global population lived within $100 \mathrm{~km}$ of the coast and less than $100 \mathrm{~m}$ above sea level. Thus, flooding can cause serious effects on human activities and properties in coastal cities which is amply reflected by Hallegatte et al [3], who predicted that the economic losses due to flooding alone in coastal cities are expected to be around US $\$ 1$ Trillion by 2050.

This escalation of damage will be caused by a number of reasons. On the one hand, cities, particularly in the global south, are undergoing rapid landuse change due to population growth and migration and increasing industrialization [6-8]. On the other, the coastal and estuarine cities are 
threatened by increasing water levels due to both sea-level rise and changes in the upstream flow patterns [9]. On top of these there is the possibility that flooding might increase due to the local rainfall regime connected to both global climate change and the local land-use driven microclimate changes [10].

The ability to predict the changes in the flood hazard and risk under variety of internal (e.g., landuse) and external (e.g., climate) forcing scenarios plays an important role in flood risk management under a rapidly changing environment. Traditional modelling applications in the domain of flood risk management typically involved developing detailed flood models and conducting a handful of flood simulation exercises. Such an approach works adequately under the assumption that the forcing variables and the model conditions can be represented by such a limited repertoire of scenarios-in other words ignoring the uncertainty of those parameters. Due to rapid and uncertain changes in the forcing parameters, flood risk management in the modern context, is demanded to embrace much more statistically robust approaches. In this context, probabilistic forecasts are a fundamental requirement for quantitative flood risk assessments, which aid urban planners and decision makers to develop informed risk reduction strategies that minimize the damage caused by floods. This is especially important for coastal cities which are not only facing the impact of upstream flow changes due to human interventions (upstream dam construction) and the effects of climate change, but also climate change driven sea level rise, storm surges as well as other natural processes such as land subsidence in deltas.

Hydraulic models that simulate river flow and flooding are needed to estimate water level changes under various future scenarios. With the rapid development of computing facilities over the last few decades, many different hydrodynamic models (e.g., MIKE11, MIKEFLOOD, ISIS, HEC-RAS, SOBEK, LISFLOOD-FP, Delft 3D) have been developed to address complex real-world hydraulic problems including flood forecasting [11,12]. Most of these developed in a direction of more and more complex and sophisticated modelling approaches in order to achieve highly precise and (oftentimes) spatially-explicit, results. In addition, many of these models are complex models that are proprietary and commercial. These factors limit their appeal for wide-spread use in flood forecasting, especially in developing countries with limited financial and technological resources. Moreover, the way in which simulation models are applied has undergone a paradigm shift in recent years: traditionally these were strictly limited to the domain of modelling specialists. However, with the emergence of wider-stakeholder engagement in co-learning, co-designing and co-solving of problems and resulting social-learning have become commonplace [13]. There is a need for simulation models which are more accessible and versatile. There is thus a need for non-restrictively licensed (e.g., open source), simple models for the wide-spread deployment in contemporary co-learning environments.

Probabilistic flood forecasting requires flood models that are simple and fast. Taking into account the large uncertainties in the future forcings and different model parameters, high degree of accuracy of models, which are sought after in deterministic applications, often become secondary to their simplicity in use and rapidity in execution in probabilistic applications. This demands models that are fit-for-purpose by being fast in execution and simple to be deployed in iterative contexts to realize thousands of models runs.

This study focuses on the development of such a 'fit-for-purpose' modelling approach suitable for probabilistic flood forecasting which also accounts for forcing and system uncertainty. Herein, we describe the application of this modelling approach to forecast flood at a selected developing country case study: Can Tho city in Mekong Delta, Vietnam.

In the following sections, we describe the study area, followed by a review of previous modelling studies in the Mekong Delta including an overview of the hydrodynamic models that have been used in those studies. This is followed by the research methodology used in this study. Then we present the results obtained and discussion. The final section of this article is main conclusions arising from the study. 


\section{Study Area}

\subsection{Mekong Delta}

The Mekong River originates from Tibet, and flows through China, Laos, Myanmar, Thailand, Cambodia and into the East Sea of Vietnam (Figure 1a). With a length of $4800 \mathrm{~km}$ and a mean annual flow of $475 \mathrm{~km}^{3}$, the Mekong River ranks twelfth and tenth in the world in term of length and flow, respectively $[14,15]$.

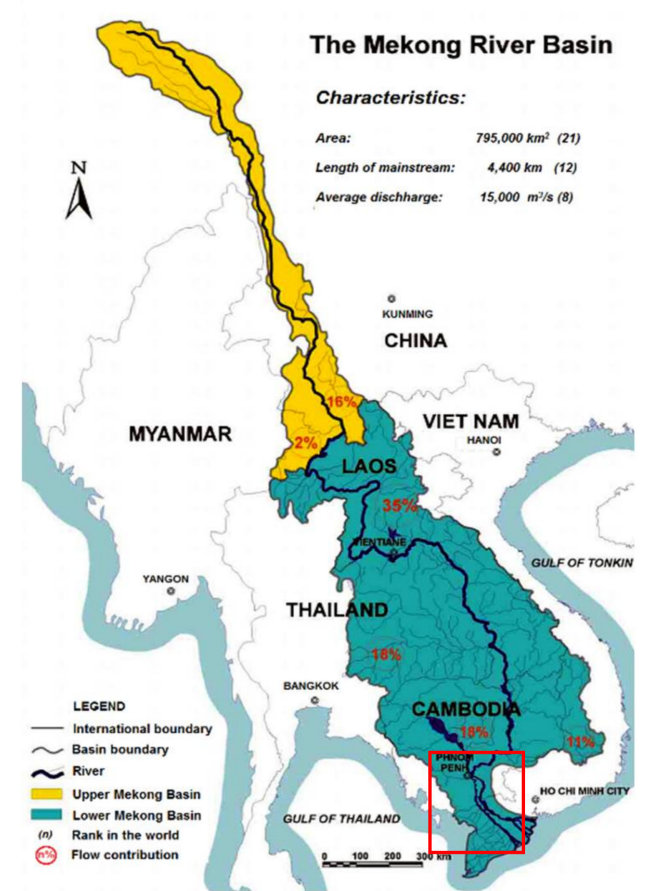

(a)

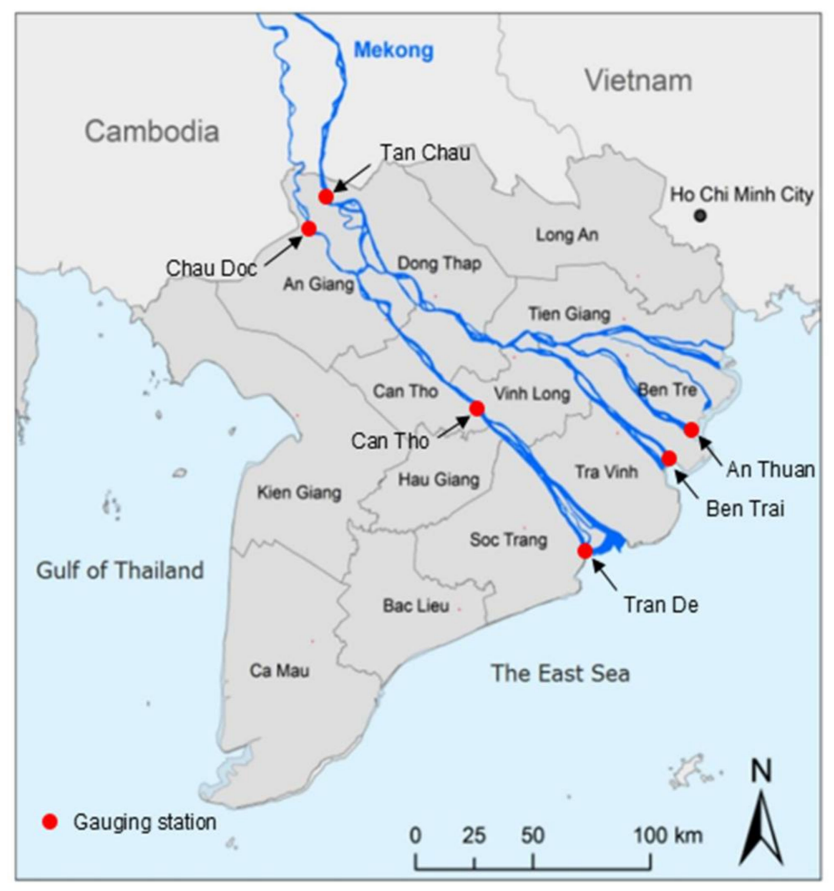

(b)

Figure 1. (a) Location of the Mekong Delta (Source: Mekong River Commission, Phnom Penh, Cambodia); (b) Detailed descriptions of the Mekong Delta include Can Tho city and 12 provinces as well as the location of hydrological gauging stations (revised from [16]).

The Mekong Delta is the largest delta of Vietnam, and is located in the lower Mekong River Basin (Figure 1), spanning latitudes $8^{\circ} 33^{\prime} \mathrm{N}$ and $11^{\circ} 01^{\prime} \mathrm{N}$ and longitudes $104^{\circ} 26^{\prime} \mathrm{E}$ and $106^{\circ} 48^{\prime} \mathrm{E}$. It includes Can Tho city and the 12 provinces: Long An, Dong Thap, Vinh Long, Tien Giang, Tra Vinh, Ben Tre, Hau Giang, Soc Trang, Bac Lieu, Kien Giang, An Giang, and Ca Mau, with a total land area of about 4 million ha. The Mekong Delta has a population of approximately 17.5 million, accounting for $19 \%$ of the country's population, while this region accounts for only $13 \%$ of the country's area. The livelihoods of a majority of the population (85\%) in the region depend on agricultural activities [17]. The Mekong Delta is known as the granary of the nation and is also a key area for the production of fishery, fruit and agricultural products. Annually, it contributes about $90 \%$ of rice, $70 \%$ of fruit, and $60 \%$ of fishery products in the national export turnover for each class. The economic growth of the region reached $7.39 \%$ in 2017, up $0.49 \%$ compared to 2016 (6.9\%). The per capita income in the Mekong Delta is about 40.2 million VND (around 1770 USD). Furthermore, the Mekong Delta is also known as one of the most biologically diverse in the world with abundant fauna and flora (e.g., fish, lizards, mammals, etc.), including rare species such as Laotian rock rat, is thought to be extinct.

The Mekong Delta has low and flat terrain, with an average elevation of between 0.7 and $1.2 \mathrm{~m}$ above mean sea level [18]. Mekong Delta is also thought to be one of areas that are globally most sensitive to the impacts of climate change $[19,20]$. The most prominent reason for the climate sensitivity of the Mekong Delta is the strongly felt influence of the sea-level rise. For example the Can Tho city 
(explained below) that is some $80 \mathrm{~km}$ upstream from the ocean, is still impacted by tidal variation (and hence any changes in the sea level in the future). For example, the cities drainage system cannot discharge water to the river during the high tide periods [9].

Besides sea level rise, climate change is likely to also affect the riverflow in the Mekong Delta, due to projected changes in temperature and rainfall [21,22]. Future projections of the upstream flow in the Mekong Delta presented by, among others, [23-25] indicate increases in riverflow for all IPCC RCPs. In addition to climate change, riverflow is also affected by human activities such as land-use change, upstream dam construction. The foreshadowed construction of new upstream hydropower dams is expected to vary the riverflow regime [24,26], with the flow varying from year to year depending on hydropower operations [27].

While flooding (which usually occurs between July and November) in the Mekong Delta has many negative impacts (e.g., damage to property, infrastructure, and crops, loss of life) on inhabitants and economic development of the area it also has some positive impacts such as washing away salt and alum from soil, providing supplementary fertiliser for rice fields, and increasing fish resources $[17,28]$. The threat of flooding in future will be undoubtedly be affected by both climate change and human interventions as described above $[18,29,30]$.

\subsection{Can Tho city}

Can Tho is the largest city within the Mekong Delta, with a population of around 1.6 million as of 2016, is the city located on the south bank of the Hau River, one of two major branches of the Mekong River in Vietnam, at a distance of about $80 \mathrm{~km}$ upstream of the sea (Figure 2). Can Tho has a dense system of rivers and canals, and therefore, it is also known as "the municipality of river water region".

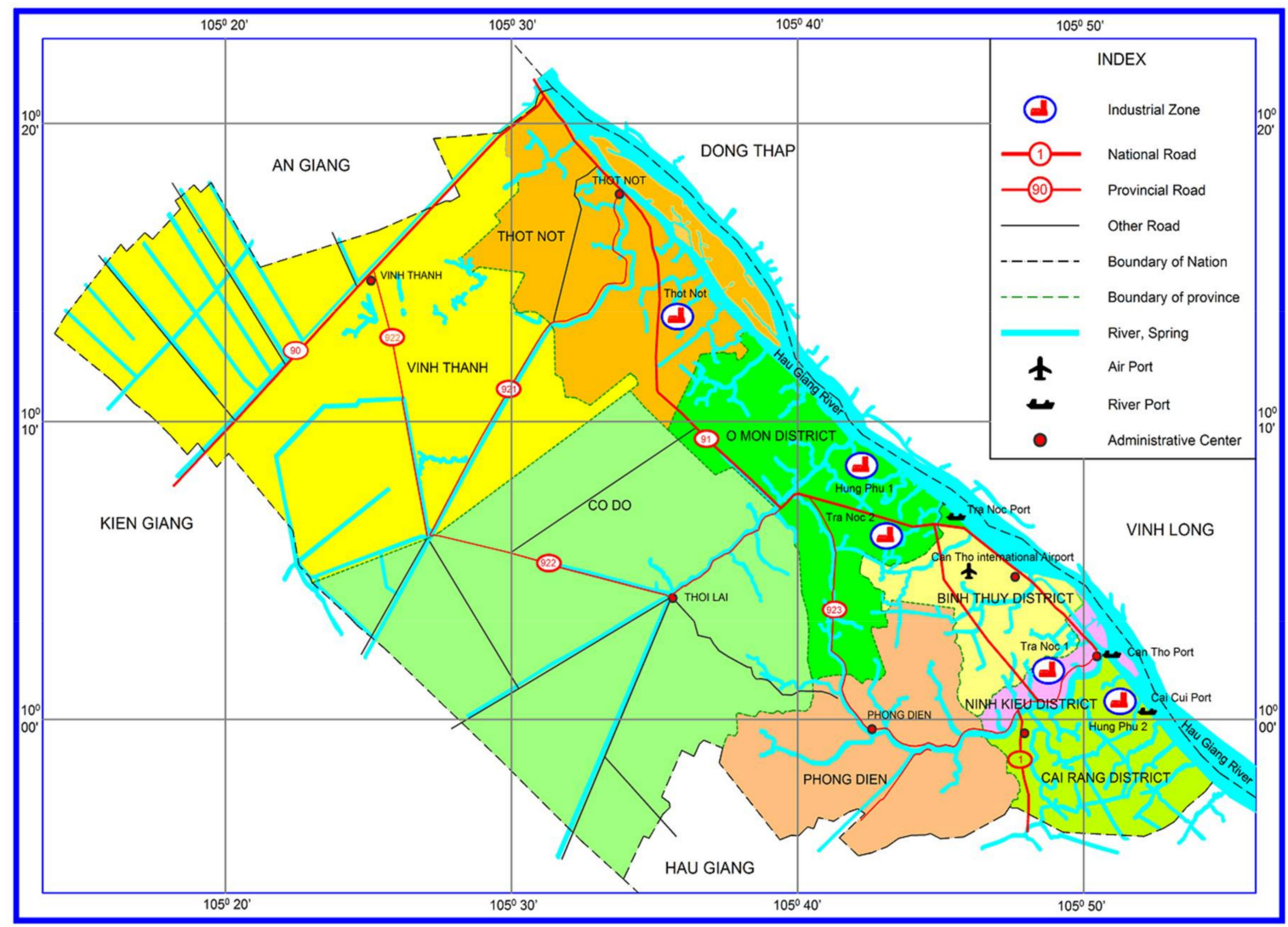

Figure 2. A map of Can Tho city. The area shown here extends much beyond the urban center. The urban area is largely in lower right corner of the diagram, north of the Can Tho river. 
Can Tho is dynamic city that is emerging as an economic centre and is expected to play an important role in the Mekong Delta and the adjacent international regions in future [9,31]. With its strategic location, Can Tho city is expected to witness growth exponentially in the next several decades [9,32]. The rapid urbanization and growth of population in Can Tho will likely lead to a significant change in land use within and surrounding area of the city [9]. This may result in substantial changes in the urban water cycle, increasing flood frequency and water pollution, all of which will further increase the city's already high risk of flooding in the coming decades.

Serious flooding is frequent in Can Tho City, which leads to significant impacts on environment, economy and society. Flooding occurs at least 2-3 times a year during the monsoon season, with flood water depths ranging from a few centimetres up to 20-30 $\mathrm{cm}$ (even up to $50 \mathrm{~cm}$ in some places such as Ninh Kieu district). According to Southern Hydrometeorology Station, in 2011, the maximum water level reached $2.15 \mathrm{~m}$ relative to mean sea level. Table 1 shows the water level in Can Tho city in flooding years.

Table 1. Water level and discharge in flooding years in Can Tho (relative to MSL) since 2000 (Source: Adapted from [33]).

\begin{tabular}{ccccc}
\hline \multirow{2}{*}{ Year } & Date & \multirow{2}{*}{ Highest Water Level $(\mathbf{c m})$} & \multicolumn{2}{c}{ Average Discharge in Can Tho $\left(\mathbf{m}^{\mathbf{3}} / \mathbf{s}\right)$} \\
\cline { 3 - 5 } & & & On Day of Flooding & Highest Flow in Month of Flooding \\
\hline 2000 & $30 / 09$ & 215 & 13,000 & $(23 / 09) 17,700$ \\
2011 & $27 / 10$ & 213 & 16,100 & $(05 / 10) 19,600$ \\
2013 & $20 / 10$ & 208 & 12,290 & $(30 / 10) 18,180$ \\
2014 & $10 / 10$ & - & - \\
\hline
\end{tabular}

Flooding in the city is significantly impacted by three factors: (1) sea level (tide, storm surge, sea-level rise) has a direct impact on the river level near Can Tho and hence the dynamics of flooding; (2) Changes in the upstream river flow, which is impacted by landuse change, construction of hydraulic structures such as dams [27,34-36]; and (3) Urban hydrology (changes in local rainfall, landuse, etc.). In order to represent the first two factors above, a physically-based simulation model of the river system of the Mekong Delta is essential. With such a model it is possible to use sea-level changes and upstream flow changes as boundary conditions to ascertain their impact on the river water level near Can Tho city and therefore the impact on floods in the city.

In the next section, therefore, we summarize previous attempts to develop such river system models for the Mekong delta.

\section{Previous Flood Modelling Studies in the Mekong Delta}

Wassmann et al. [30] used the "Vietnam River System and Plains" (VRSAP) model to assess the water level changes in the Vietnamese Mekong Delta (VMD) due to the impacts of sea level rise (SLR). The VRSAP model was developed by the Sub-Institute for Water Resources Planning, Ministry of Agriculture and Rural Development, Vietnam (Khue, 1986). The VRSAP model for whole VMD included 1505 nodes, 2111 segments, and 555 storage plains. It was calibrated with hydrological data obtained in 1996, and then used to predict water levels for years 2030 and 2070. This model projected water levels for VMD when flooding is presently high (from August to November) for SLR projections of $20 \mathrm{~cm}$ (in 2030) and $45 \mathrm{~cm}$ (in 2070), respectively. The results of this study indicated that the average increase in August water levels corresponding to the two considered scenario were $14.1 \mathrm{~cm}$ and $32.2 \mathrm{~cm}$, respectively, relative to 1996. In October, the increase in water levels were found to be weaker due to high discharge from upstream, but the average increases for the two considered scenarios were still high at $11.9 \mathrm{~cm}$ and $27.4 \mathrm{~cm}$, respectively.

Le et al. [37] used the HydroGis model, which combines a hydrodynamic model and GIS tools [38], was developed by the Ministry of Natural Resource and Environment of Vietnam (MONRE) to evaluate changes in flooding in the VMD due to the combined effect of upstream river flows, storm surge, SLR, estuarine siltation, and hydraulic structures. The HydroGis model for the entire VMD comprised 
13,262 cross sections, 2535 flood cells, and 467 sewers, sluices, and bridges. This study indicated that the flood levels depend on the combined impacts of Mekong river flows, storm surges and SLR as well as the construction of upstream dams. Water levels in the delta were predicted to increase from $5 \mathrm{~cm}$ to $200 \mathrm{~cm}$ corresponding each scenario. Additionally, this study predicted that the construction of upstream dams would cause siltation the Hau river estuary and followed by the increase by up $2 \mathrm{~m}$ in peak flood levels in the VMD.

HR Wallingford and Halcrow (UK) developed a 1-D ISIS model for the VMD to assist the Mekong River Commission (MRC) in managing and using water resources in the Mekong River Basin (MRB). Currently, this ISIS model is maintained by the MRC. MRC's detailed modelling studies for Cambodia and the VMD have used the results of this model as boundary conditions. Van et al. [39] used this model to study changes of flood characteristics under the impacts of upstream development and SLR. The 1-D ISIS model for the VMD comprised 3036 cross-sections representing $8619 \mathrm{~km}$ system of river and canals, 538 junctions, 749 floodplain units, 193 spillways, 409 reservoirs, and 29 sluices. This study used the flood event data of the year 2000 to validate this model, and subsequently used it to predict potential changes in flooding for the year 2050 under scenario $3 \mathrm{a}$ and $3 \mathrm{~b}$. The results showed that the flood hazard in 2050 may become more severe along the coastal area as a result of the tidal regime. Additionally, future (2050) inundation levels in upstream VMD were projected to be lower and shorter than in 2000, while along the coastal areas would be higher and longer.

All the models applied in the aforementioned studies are advanced process based hydrodynamic models with superior features, and as such the model outcomes are expected to be highly accurate and reliable. However, these models do take a long time for extended period simulations, owing to the large and complex application domain. For example, the time for the aforementioned ISIS model of VMD to complete a one-year simulation is about $90 \mathrm{~min}$ (on a single core on an Intel(R) Core(TM) i5-4210M CPU @ 2.6 GHz 2.6 GHz processor in a computer with $8.0 \mathrm{~GB}$ of memory (RAM)). With such a computational time, it is impractical to execute the thousands of individual simulations required for probabilistic flood forecasting with this model.

In the next section we describe the methodology that was used to develop a fit-for-purpose model that is fast and simple enough to be deployed in probabilistic water level calculations near Can Tho city, which in-turn can be used to force urban flood models.

\section{Methodology}

\subsection{Data}

The data for this study were collected from two sources: (i) upstream flow (discharge) from 2000 to 2006, measured water level in 2000 at Chau Doc, Tan Chau, Can Tho, Tran De, Ben Trai and An Thuan stations (Figure 1b), cross-section data and the Manning's roughness coefficient of links were taken from the aforementioned Mekong Delta 1-D ISIS model of the MRC. Additionally, discharge in 2011 was collected from MRC as well; (ii) measured water level of the years 2001, 2002 and 2011 at six above gauging stations were collected from the National Hydro-meteorological Service of Viet Nam (NHMS).

\subsection{Model Selection}

To circumnavigate the complexities arising due to simulation time and proprietary nature of sophisticated process based models such as those used in the studies summarized in Section 3 above, here, to achieve the objective of this study, we used the open-source SWMM model. SWMM is a dynamic rainfall-runoff simulation model used for single event or long-term (continuous) simulation of runoff quantity and quality [40].

The application of the SWMM model for this task was unconventional. This decision was made based on a number of considerations. Firstly, the SWMM implementing full St. Venant's equation in one dimensional conduits [40], is technically capable of simulating the required flow conditions in this complex river system. It can manage complex flow conditions such as downstream forcing by 
tide. Secondly, it provides a simple, uncluttered user interface that is simple enough to be deployed in multi-stakeholder co-design sessions. Finally, being a public-domain, open source model, and it is not bound by restrictions associated with commercial licenses. Although commercial licensing is not always a significant barrier for a model to be used by experts in, for example, a consulting environment, delivering a model for wider use by non-expert stakeholders is sometimes severely hampered by such restrictions.

\subsection{Model Application}

\subsubsection{SWMM Model Development and Simplification}

In the first step of this study, a very detailed SWMM model of the entire Mekong Delta, comprising 575 nodes and 592 conduits, was developed (Figure 3). This model covered only the important tributaries of the Mekong, ignoring small canals and other waterways.

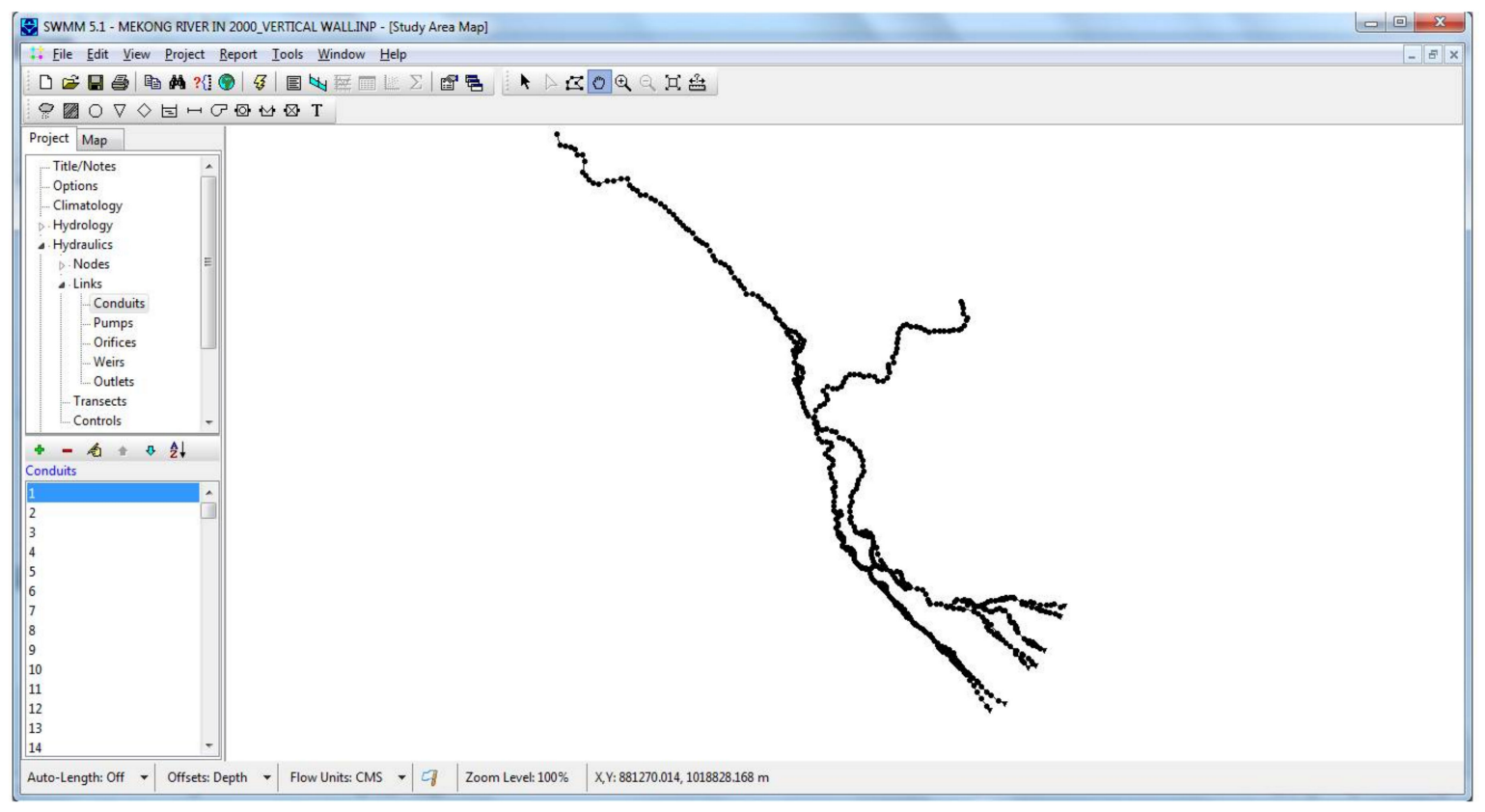

Figure 3. The detailed SWMM model for Mekong Delta with 575 nodes and 592 conduits.

The input data used were the daily upstream flow and hourly downstream sea level in 2000 . This model is already simplified compared to many of the models described in the section above and took about $10 \mathrm{~min}$ for a one year simulation (for details see Table 11). The next step is to reduce the model complexity such that very fast individual simulations are possible. To this end, a series of simulations (hourly temporal resolution) of the detailed SWMM model were undertaken where the level of detail in the model was gradually decreased (i.e., systematic removal of small to medium size tributaries, based on their size and/or distance from target area). In doing this here nodes that appeared to be at non-critical locations were sequentially removed from the system while retaining nodes at critical locations where there were river branch divisions, changes in the direction of flow, significant changes in cross-sectional area, hydrological stations, etc. The model obtained after each stage in the reductions process was run for the year 2000, and results compared with measured water levels at Chau Doc, Tan Chau and Can Tho stations in 2000. If the post-reduction model results were still good enough, the process of reduction was continued until the simplest level of detail that provides sufficiently accurate predictions of water levels in the local study area (Can Tho, Vietnam) was obtained. The final model thus obtained is referred to herein as the simplified SWMM model. The Simplified SWMM model took only a minute to complete one year period of simulation, representing a 10 and 
90 fold reduction in run time relative to the detailed SWMM model and the detailed ISIS model described above (see also Table 11).

\subsubsection{Model Calibration and Validation}

\section{Model Calibration}

An automatic calibration of the simplified SWMM model was undertaken for the year 2000 using observed hourly water levels at Chau Doc, Tan Chau and Can Tho stations. The SWMM5-EA software [41], which uses evolutionary algorithms to optimize drainage networks, was used to optimise the Manning's roughness coefficient of conduits of the simplified SWMM model.

Water levels at the gauging stations in the Mekong Delta sharply change between flood season and dry season. Therefore, monthly NSE (Nash-Sutcliffe efficiency) and RMAE (Relative Mean Absolute Error) values of the 3 gauging stations Can Tho, Chau Doc and Tan Chau were used for model calibration.

- NSE indicator

The NSE is a normalized statistic that determines the relative magnitude of the residual variance ("noise") compared to the observed data variance ("information") [42]. Model performance is commonly classified for various ranges of the NSE as shown below [42].

- $\quad 0.75<$ NSE $\leq 1.00:$ Very Good;

- $\quad 0.65<\mathrm{NSE} \leq 0.75$ : Good;

- $\quad 0.50<$ NSE $\leq 0.65$ : Satisfactory;

- $\quad$ NSE $\leq 0.50$ : Unsatisfactory.

\section{- RMAE indicator}

The RMAE is a commonly used error statistic [43].

Model performance is commonly classified for various ranges of the RMAE as shown below (Sutherland et al., 2004).

- $\quad$ RMAE < 0.20: Excellent;

- $\quad 0.20 \leq$ RMAE < 0.40: Good;

- $\quad 0.40 \leq$ RMAE < 0.70: Reasonable;

- $\quad 0.70 \leq \mathrm{RMAE} \leq 1.00$ : Poor;

- $\quad$ RMAE > 1.00: Bad.

Model Validation

Model validation was performed manually for the years 2001, 2002 and 2011, using the model calibrated with the year 2000 data, to gain confidence in model predictions. Results of the validation simulations were compared with hourly water level data acquired at Chau Doc, Tan Chau and Can Tho stations.

\section{Results and Discussion}

\subsection{Calibration of the Simplified SWMM Model}

After a number of trials with varying levels of complexity, a simplified model where the number of nodes and conduits were 37 and 40 respectively (Figure 4), was determined to have a positive result (see Tables 4 and 5) while being sufficiently fast ( 1 min run time for a 1 year simulation period at hourly temporal resolution). Figures 5 and 6 show the comparison between simulated water levels with observed water levels at Can Tho station in 2000. 
The results of the simplified SWMM calibration for year 2000 is shown in Table 2. Scatter plots of simulated and observed hourly water level of each month in 2000 at Chau Doc, Tan Chau and Can Tho stations are shown in Figures 7-9, respectively.

Table 2. Data sources.

\begin{tabular}{|c|c|c|}
\hline Data Type & Source & Data Description \\
\hline Discharge & MRC & Daily discharge data at upstream (2000-2006) and 2011 \\
\hline Cross-section & MRC & $\begin{array}{l}3036 \text { cross-sections representing } 8619 \mathrm{~km} \text { system of river and } \\
\text { canals in the Mekong Delta }\end{array}$ \\
\hline Manning's roughness & MRC & 10 different values of Manning's roughness coefficient \\
\hline \multirow{2}{*}{ Measured water level } & MRC & $\begin{array}{l}\text { Hourly water level data at Chau Doc, Tan Chau, Can Tho, } \\
\text { Tran De, Ben Trai and An Thuan stations in } 2000\end{array}$ \\
\hline & NHMS & $\begin{array}{l}\text { Hourly water level data at Chau Doc, Tan Chau, Can Tho, Tran } \\
\text { De, Ben Trai and An Thuan stations in 2001, 2002, and } 2011\end{array}$ \\
\hline
\end{tabular}

Based on the results in Table 3 and the classifications for NSE as well as RMAE, error classification for NSE and RMAE indicators for each station in 2000 are shown in Tables 4 and 5 respectively.

Table 3. General performance rating for the model for the calibration period (year 2000) using the NSE and RMAE indicators (hourly resolution).

\begin{tabular}{lcccccc}
\hline \multirow{2}{*}{ Month } & Station & \multicolumn{2}{c}{ Chau Doc } & \multicolumn{2}{c}{ Tan Chau } & \multicolumn{2}{c}{ Can Tho } \\
\cline { 2 - 7 } \multicolumn{1}{c}{ Nanuary } & NSE & RMAE & NSE & RMAE & NSE & RMAE \\
February & -0.89 & 0.05 & -0.89 & 0.12 & 0.67 & 0.04 \\
March & -0.14 & 0.01 & 0.16 & 0.09 & 0.71 & 0.12 \\
April & 0.02 & 0.07 & 0.37 & 0.13 & 0.72 & 0.10 \\
May & 0.04 & 0.16 & 0.51 & 0.21 & 0.75 & 0.80 \\
June & 0.27 & 0.19 & 0.34 & 0.28 & 0.74 & 0.17 \\
July & 0.54 & 0.07 & 0.41 & 0.16 & 0.68 & 0.40 \\
August & 0.03 & 0.16 & 0.76 & 0.05 & 0.71 & 0.09 \\
September & -16.78 & 0.01 & -8.54 & 0.02 & 0.72 & 0.10 \\
October & -2.41 & 0.09 & -3.15 & 0.07 & 0.81 & 0.08 \\
November & -1.05 & 0.04 & -0.92 & 0.03 & 0.76 & 0.08 \\
December & 0.77 & 0.04 & 0.59 & 0.05 & 0.71 & 0.04 \\
\hline
\end{tabular}

Table 4. Error classification (\%) for NSE indicator.

\begin{tabular}{ccccc}
\hline \multirow{2}{*}{ Station } & \multicolumn{4}{c}{ Classification for NSE } \\
\cline { 2 - 4 } & Very Good & Good & Satisfactory & Unsatisfactory \\
\hline Chau Doc & 8.33 & 0.00 & 8.33 & 83.33 \\
Tan Chau & 8.33 & 0.00 & 16.67 & 75.00 \\
Can Tho & 16.67 & 83.33 & 0.00 & 0.00 \\
\hline
\end{tabular}

Table 5. Error classification (\%) for RMAE indicator.

\begin{tabular}{cccccc}
\hline \multirow{2}{*}{ Station } & \multicolumn{5}{c}{ Classification for RMAE } \\
\cline { 2 - 6 } & Excellent & Good & Reasonable & Poor & Bad \\
\hline Chau Doc & 100.00 & 0.00 & 0.00 & 0.00 & 0.00 \\
Tan Chau & 83.33 & 16.67 & 0.00 & 0.00 & 0.00 \\
Can Tho & 83.33 & 0.00 & 8.33 & 8.33 & 0.00 \\
\hline
\end{tabular}

Based on the results in Tables 4 and 5, almost RMAE values at Chau Doc, Tan Chau and Can Tho stations are in excellent and good classifications, especially Chau Doc station with $100 \%$ values is in 
excellent classification, while Can Tho is $83.33 \%$. Nonetheless, Can Tho also has $8.33 \%$ values in total is poor classification. For NSE indicator, only Can Tho station has classifications are in very good and good with $100 \%$ in total, while Chau Doc and Tan Chau are $8.33 \%$. The main classifications of Chau Doc and Tan Chau stations are unsatisfactory with $83.33 \%$ and $75 \%$, respectively.

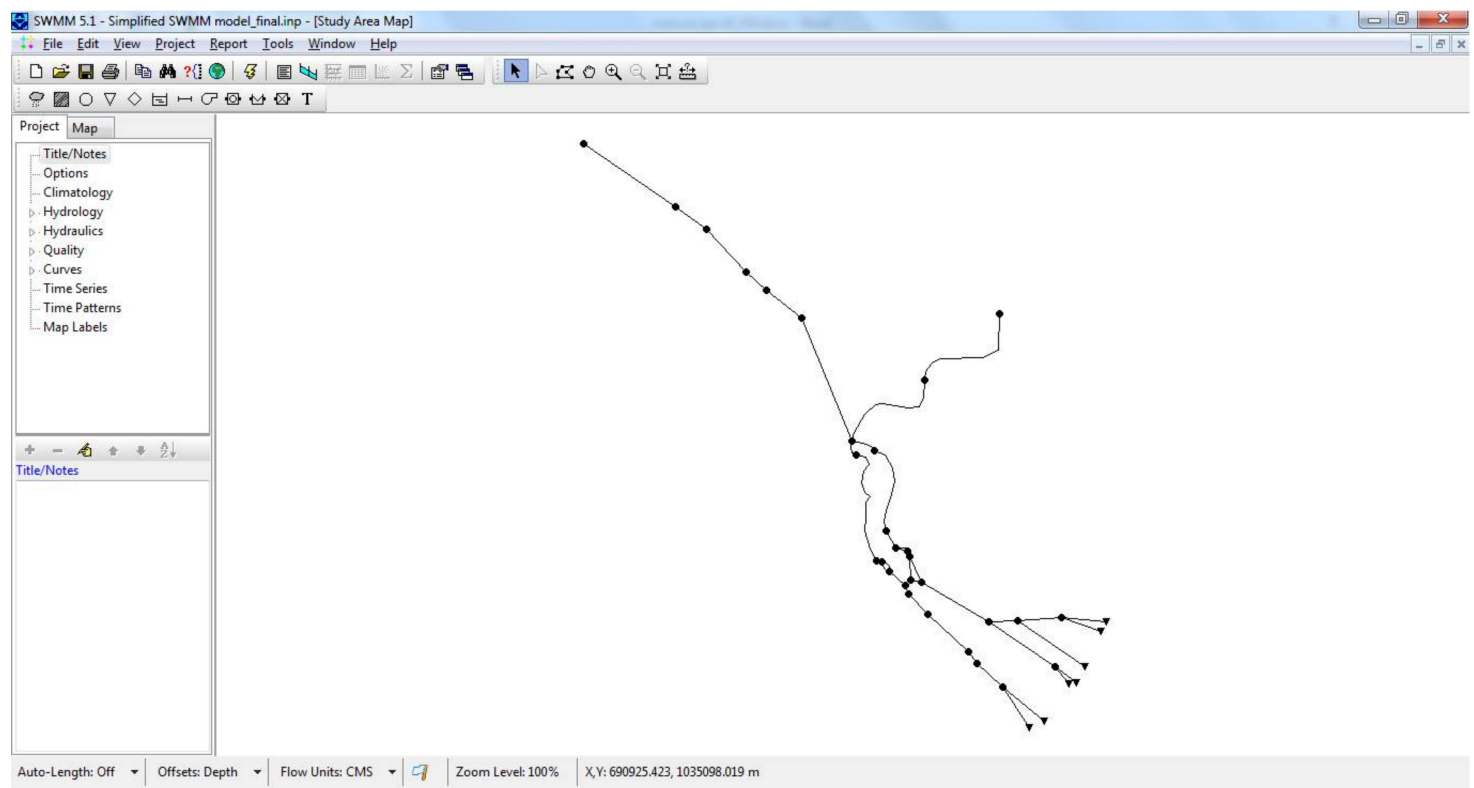

Figure 4. The simplified model for Mekong delta with 37 nodes and 40 conduits.

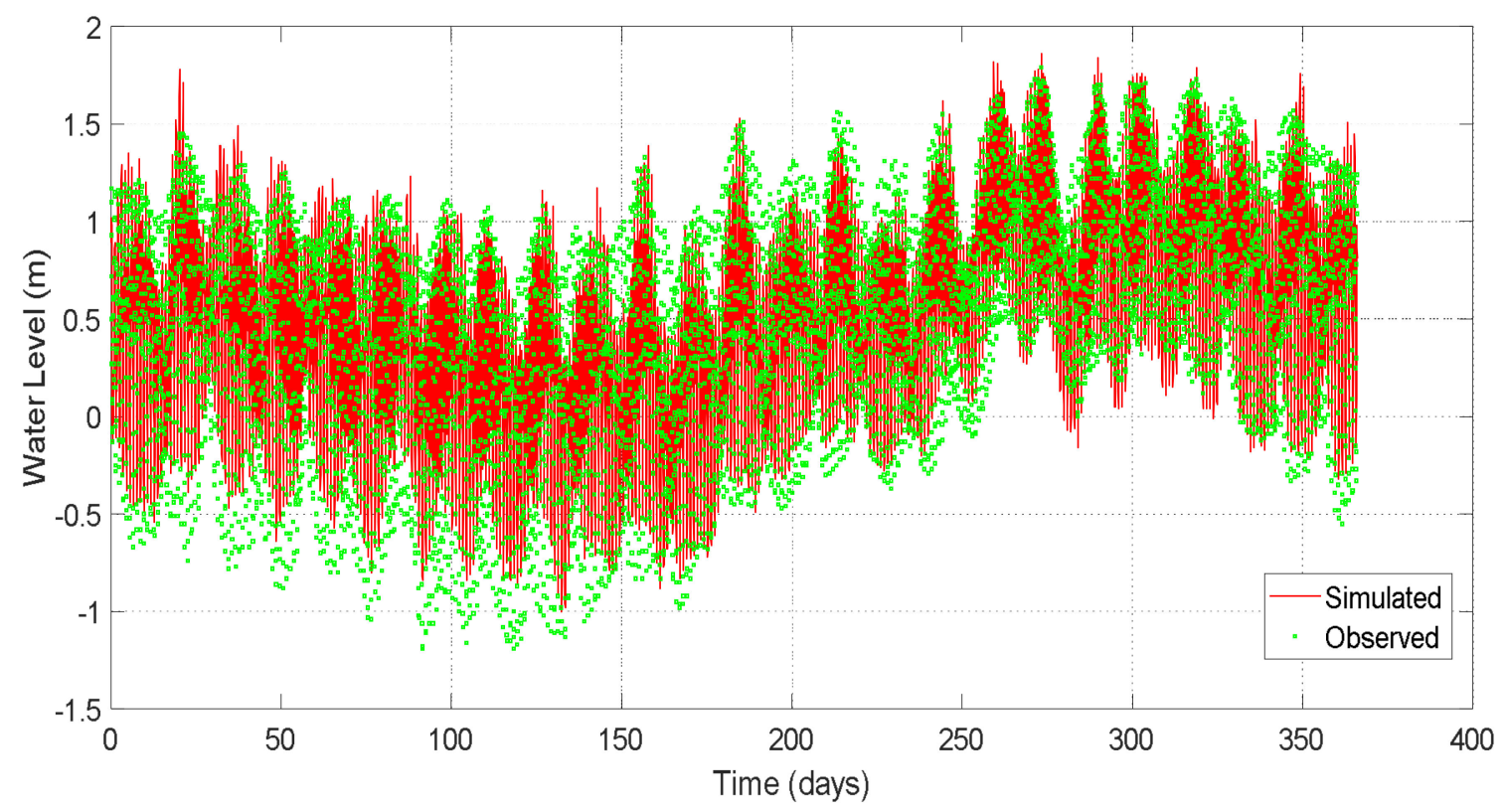

Figure 5. Comparison between simulated and observed water level (relative to MSL) time series at Can Tho station in 2000. 


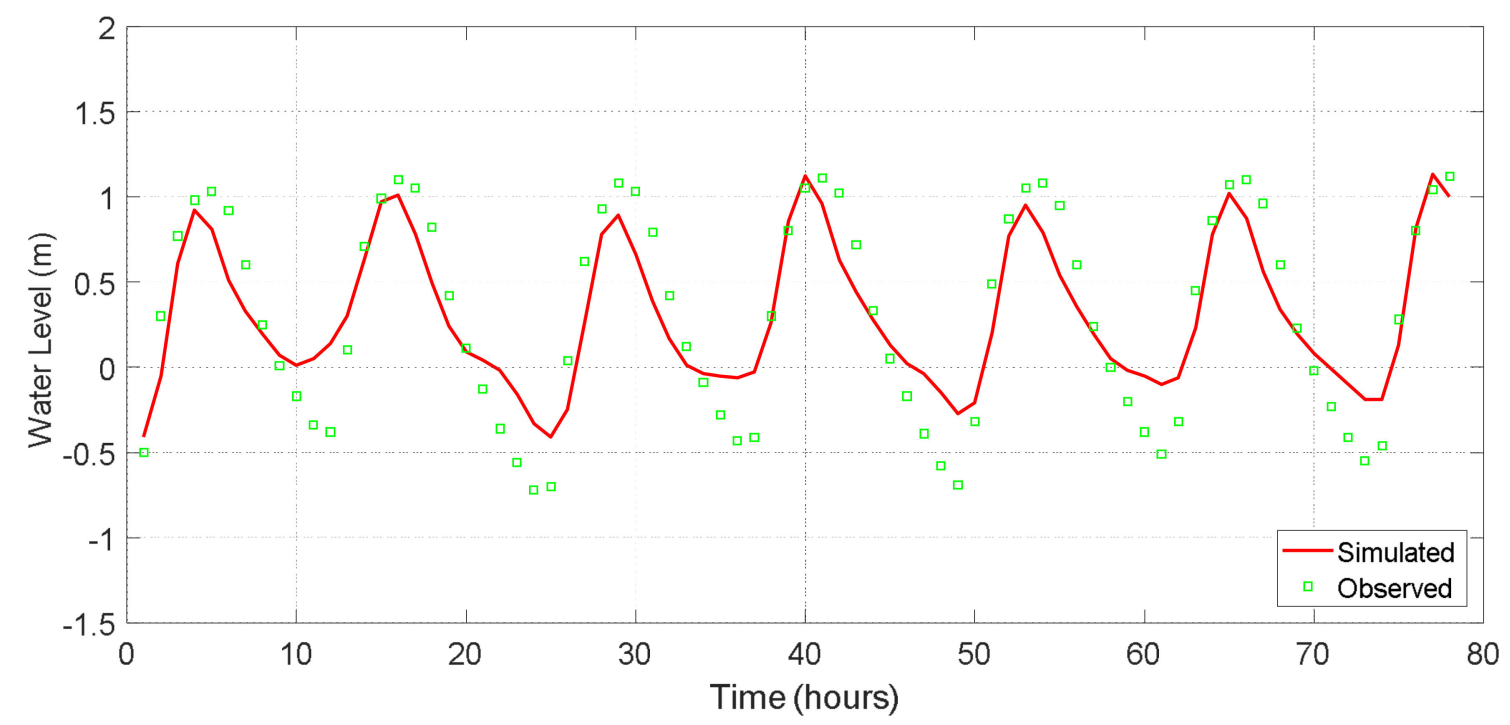

Figure 6. Zoom in of the comparison between simulated and observed water levels (relative to MSL) at Can Tho station from $07 / 03 / 2000$ to $10 / 03 / 2000$.
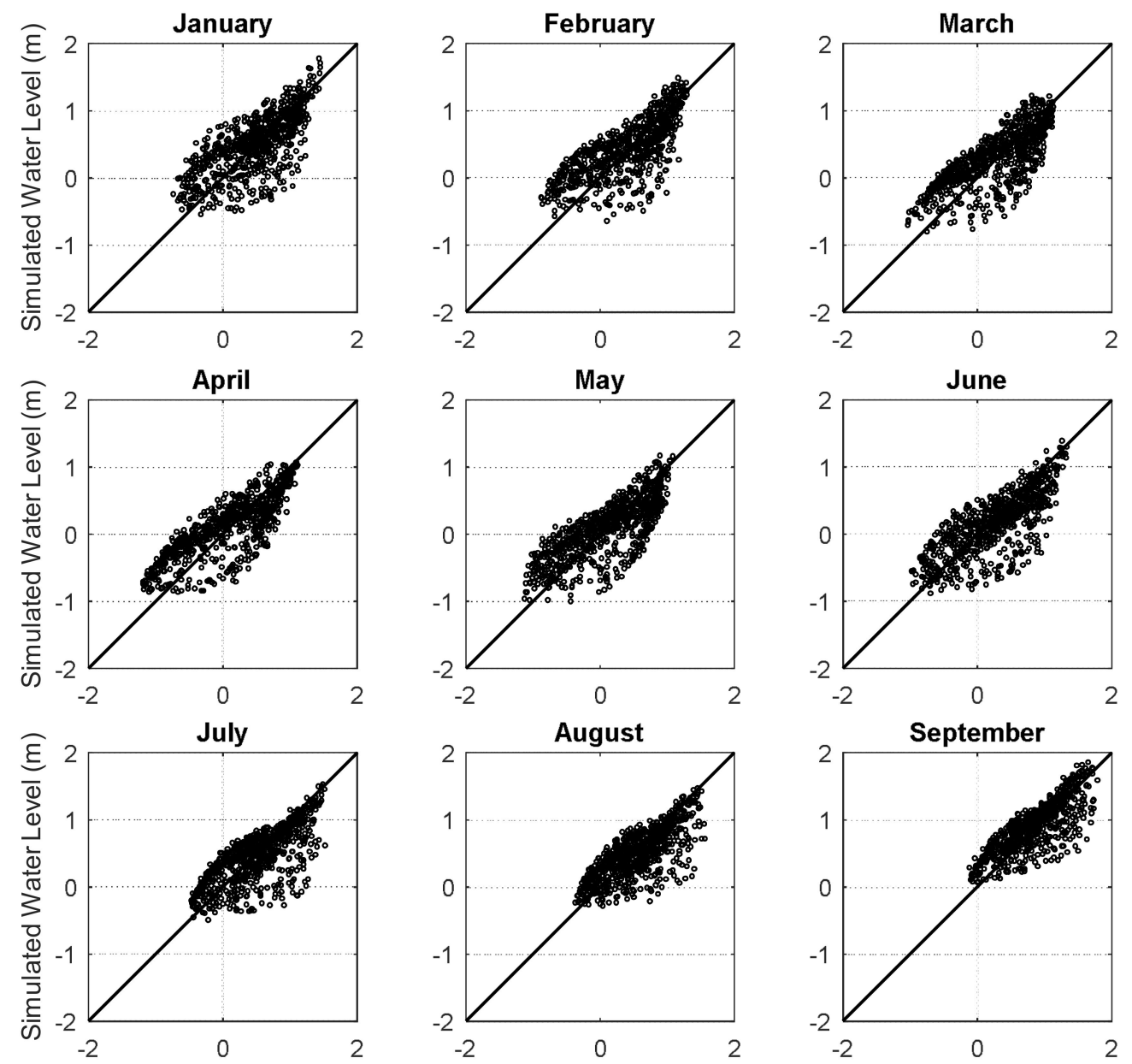

Figure 7. Cont. 

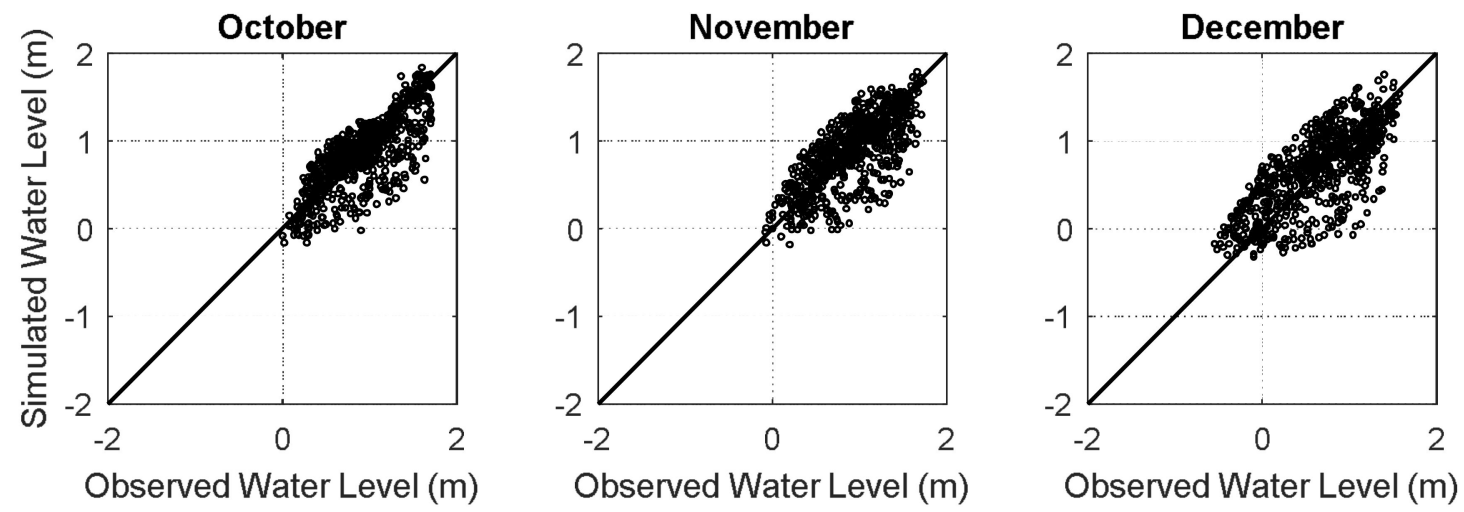

Figure 7. Scatter plots of simulated and observed hourly water level (relative to MSL) of each month in 2000 at Can Tho station.
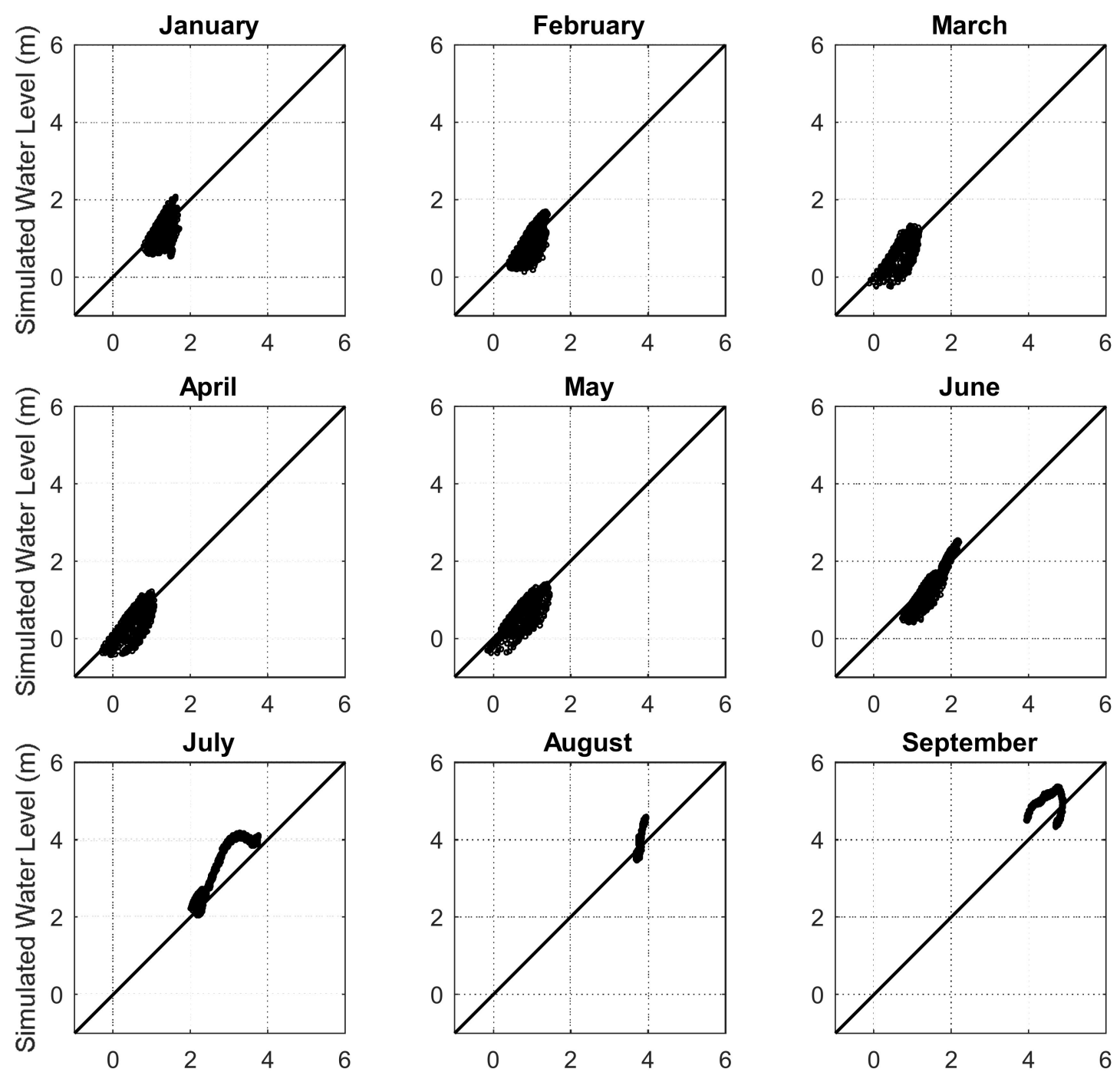

Figure 8. Cont. 

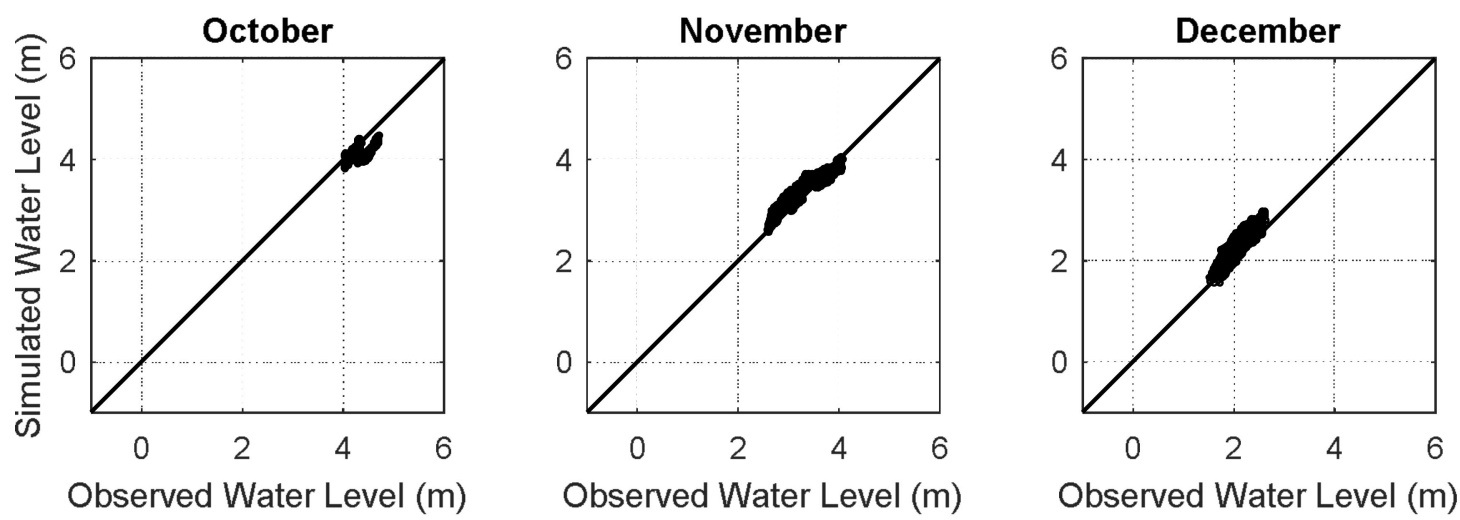

Figure 8. Scatter plots of simulated and observed hourly water level (relative to MSL) of each month in 2000 at Chau Doc station.
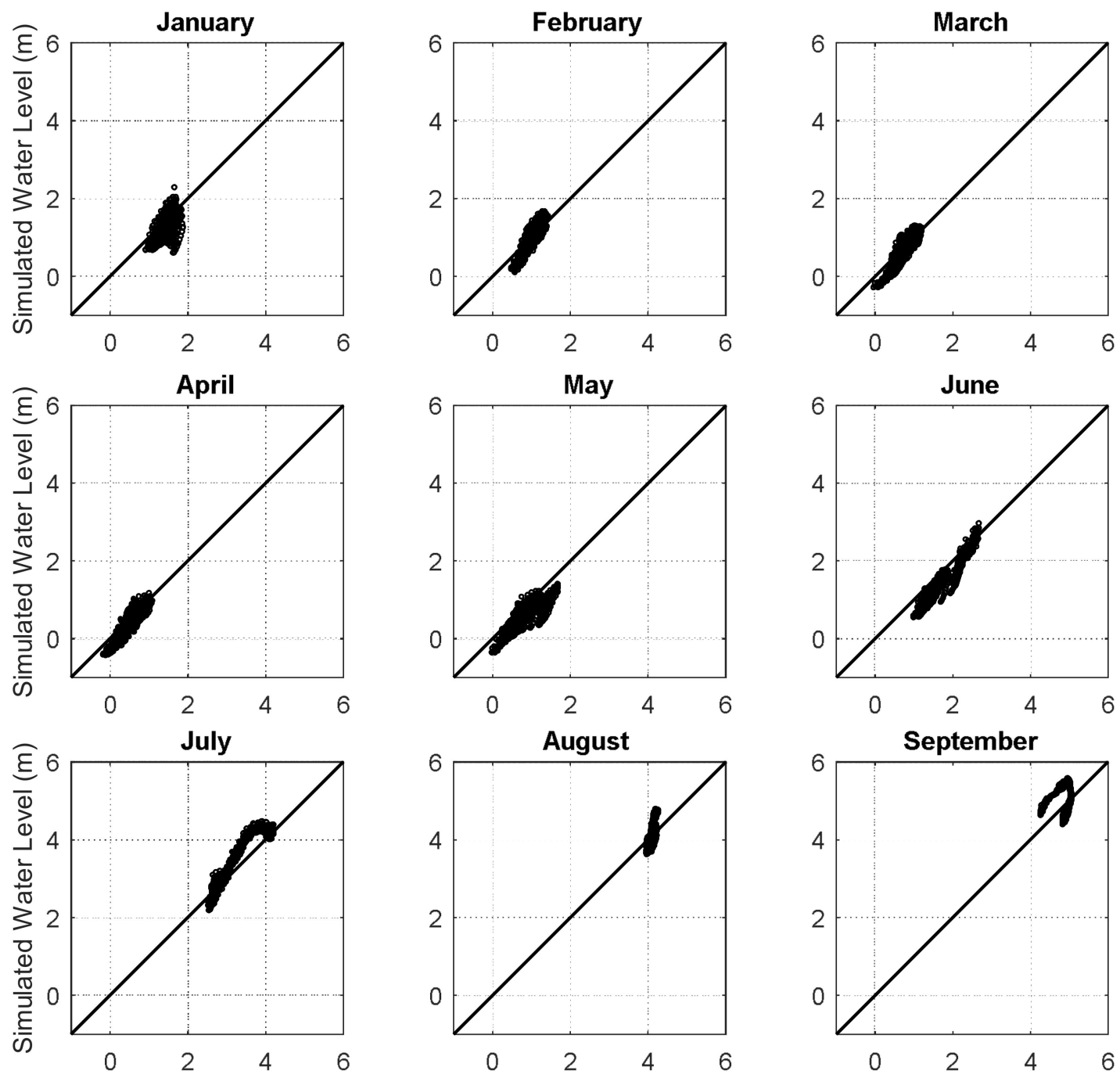

Figure 9. Cont. 

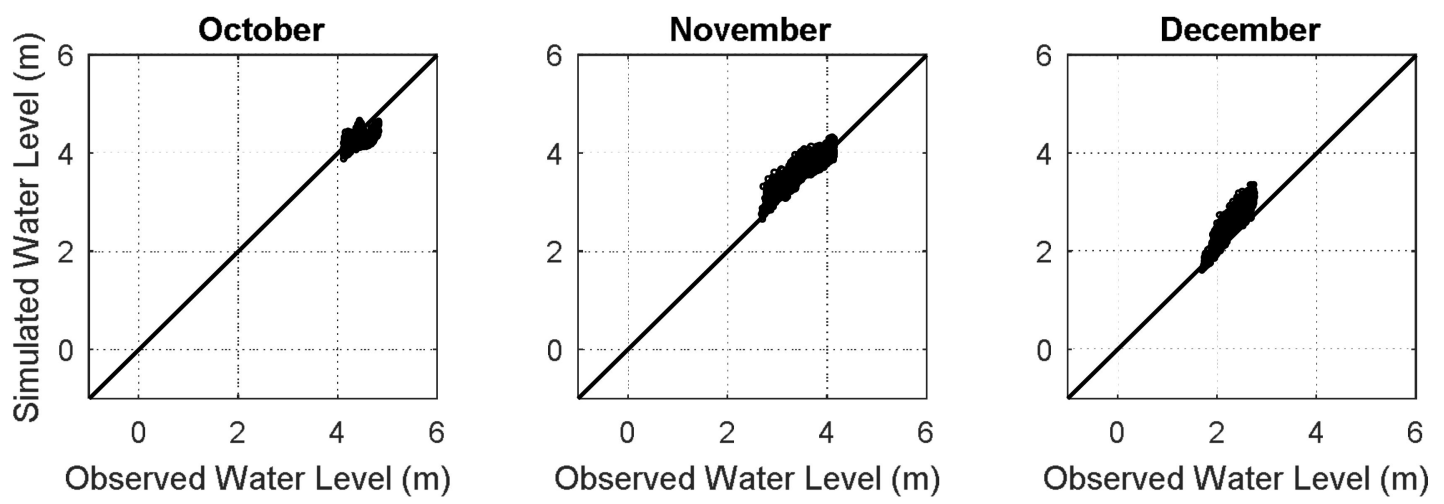

Figure 9. Scatter plots of simulated and observed hourly water level (relative to MSL) of each month in 2000 at Tan Chau station.

\subsection{Model Validation}

The results of the S-SWMM validation for 2001, 2002 and 2011 are shown in Tables 6-8, respectively.

Table 6. General performance rating for the model for the validation period (year 2001) using the NSE and RMAE indicators (hourly resolution).

\begin{tabular}{lcccccc}
\hline \multirow{2}{*}{ Month } & Station & \multicolumn{2}{c}{ Chau Doc } & \multicolumn{2}{c}{ Tan Chau } & \multicolumn{2}{c}{ Can Tho } \\
\cline { 2 - 7 } & NSE & RMAE & NSE & RMAE & NSE & RMAE \\
\hline January & -1.08 & 0.22 & -0.05 & 0.13 & 0.66 & 0.21 \\
February & 0.85 & 0.32 & 0.95 & 0.18 & 0.79 & 0.21 \\
March & 0.12 & 0.06 & 0.64 & 0.00 & 0.75 & 0.11 \\
April & 0.19 & 0.01 & 0.62 & 0.02 & 0.78 & 0.23 \\
May & 0.14 & 0.08 & 0.49 & 0.12 & 0.76 & 5.98 \\
June & 0.01 & 0.20 & -0.22 & 0.28 & 0.73 & 0.52 \\
July & 0.56 & 0.00 & 0.05 & 0.07 & 0.68 & 0.29 \\
August & 0.57 & 0.09 & 0.88 & 0.01 & 0.67 & 0.06 \\
September & -12.15 & 0.01 & -13.35 & 0.04 & 0.79 & 0.06 \\
October & 0.76 & 0.00 & 0.31 & 0.03 & 0.63 & 0.06 \\
November & 0.37 & 0.07 & 0.61 & 0.03 & 0.71 & 0.03 \\
December & -0.52 & 0.17 & -0.05 & 0.12 & 0.68 & 0.05 \\
\hline
\end{tabular}

Table 7. General performance rating for the model for the validation period (year 2002) using the NSE and RMAE indicators (hourly resolution).

\begin{tabular}{lcccccc}
\hline \multirow{2}{*}{ Month } & Station & \multicolumn{2}{c}{ Chau Doc } & \multicolumn{2}{c}{ Tan Chau } & \multicolumn{2}{c}{ Can Tho } \\
\cline { 2 - 7 } & NSE & RMAE & NSE & RMAE & NSE & RMAE \\
\hline January & -2.00 & 0.30 & -0.33 & 0.16 & 0.66 & 0.16 \\
February & 0.83 & 0.29 & 0.96 & 0.14 & 0.68 & 0.19 \\
March & 0.15 & 0.17 & 0.76 & 0.01 & 0.75 & 0.22 \\
April & -0.21 & 0.08 & 0.42 & 0.10 & 0.67 & 0.28 \\
May & 0.28 & 0.01 & 0.54 & 0.17 & 0.77 & 0.24 \\
June & 0.46 & 0.13 & -0.02 & 0.28 & 0.74 & 0.15 \\
July & 0.70 & 0.05 & 0.67 & 0.09 & 0.65 & 0.41 \\
August & 0.46 & 0.12 & 0.89 & 0.01 & 0.74 & 0.14 \\
September & -3.49 & 0.03 & -0.81 & 0.02 & 0.75 & 0.13 \\
October & 0.69 & 0.03 & 0.70 & 0.01 & 0.75 & 0.08 \\
November & -1.57 & 0.17 & -0.01 & 0.09 & 0.70 & 0.01 \\
December & -1.83 & 0.23 & -0.53 & 0.15 & 0.66 & 0.04 \\
\hline
\end{tabular}


Table 8. General performance rating for the model for the validation period (2011) using the NSE and RMAE indicators (hourly resolution).

\begin{tabular}{lcccccc}
\hline \multirow{2}{*}{ Month } & Station & \multicolumn{2}{c}{ Chau Doc } & \multicolumn{2}{c}{ Tan Chau } & \multicolumn{2}{c}{ Can Tho } \\
\cline { 2 - 6 } & NSE & RMAE & NSE & RMAE & NSE & RMAE \\
\hline January & -4.76 & 0.80 & -5.34 & 0.74 & 0.45 & 0.54 \\
February & 0.47 & 0.67 & 0.63 & 0.63 & 0.72 & 0.60 \\
March & -0.50 & 0.38 & 0.03 & 0.37 & 0.64 & 0.53 \\
April & -0.10 & 0.29 & 0.51 & 0.27 & 0.67 & 0.86 \\
May & 0.03 & 0.29 & 0.62 & 0.21 & 0.68 & 1.79 \\
June & -0.16 & 0.19 & 0.68 & 0.01 & 0.69 & 1.29 \\
July & -4.17 & 0.33 & -0.03 & 0.09 & 0.72 & 0.30 \\
August & -3.61 & 0.36 & 0.11 & 0.11 & 0.75 & 0.12 \\
September & -5.96 & 0.23 & -0.06 & 0.08 & 0.78 & 0.10 \\
October & -17.46 & 0.07 & -0.41 & 0.02 & 0.77 & 0.04 \\
November & -1.57 & 0.20 & -0.06 & 0.11 & 0.64 & 0.10 \\
December & -6.38 & 0.45 & -3.80 & 0.35 & 0.58 & 0.23 \\
\hline
\end{tabular}

Based on the results in Tables 6-8 and the classifications for NSE and RMAE, error classification for NSE and RMAE indicators for each station in 2001, 2002 and 2011 are shown in Tables 9 and 10 respectively.

Table 9. Error classification (\%) for NSE indicator in 2001, 2002 and 2011.

\begin{tabular}{ccccc}
\hline \multirow{2}{*}{ Station } & \multicolumn{4}{c}{ Classification for NSE } \\
\cline { 2 - 5 } & Very Good & Good & Satisfactory & Unsatisfactory \\
\hline Chau Doc & 8.33 & 5.56 & 5.56 & 80.55 \\
Tan Chau & 13.89 & 8.33 & 19.44 & 58.33 \\
Can Tho & 19.44 & 63.89 & 13.89 & 2.78 \\
\hline
\end{tabular}

Table 10. Error classification (\%) for RMAE indicator in 2001, 2002 and 2011.

\begin{tabular}{cccccc}
\hline \multirow{2}{*}{ Station } & \multicolumn{5}{c}{ Classification for RMAE } \\
\cline { 2 - 6 } & Excellent & Good & Reasonable & Poor & Bad \\
\hline Chau Doc & 55.56 & 36.11 & 5.56 & 2.78 & 0.00 \\
Tan Chau & 77.78 & 16.67 & 2.78 & 2.78 & 0.00 \\
Can Tho & 50.00 & 25.00 & 13.89 & 2.78 & 8.33 \\
\hline
\end{tabular}

Tables 9 and 10 show that a vast majority of RMAE values at Chau Doc, Tan Chau and Can Tho stations are in excellent and good classifications. Specifically, the percentages of data/model comparison that fall into excellent and good categories are $91.67 \%, 94.45 \%$ and $75 \%$ at Chau Doc, Tan Chau and Can Tho, respectively. However, it is noted that $2.78 \%$ of RMAE values fall into the poor category for all 3 stations, while at Can Tho 8.33\% RMAE values also fall into the bad category. With respect the NSE indicator, $83 \%, 13.89 \%$ and $22.22 \%$ of NSE values fall in very good and good categories (in combination) at Can Tho, Chau Doc, and Tan Chau stations, respectively. The majority of NSE values at Chau Doc (80.55\%) and Tan Chau (58.33\%) are unsatisfactory.

For the RMAE indicator, the poor and bad classifications are generally in the dry months (from December to June), while the good and excellent categories are generally in the wet months (from July to November). However, it is noteworthy that at Can Tho, the target area pertaining to this study, the differences between the simulated monthly mean water levels and the measured monthly mean water levels are small even during wet months, the maximum value is $0.15 \mathrm{~m}$. As the main focus of this study is flooding during wet months at Can Tho, the weaker data/model comparison, 
especially during dry months, at the secondary stations of Chau Doc and Tan Chau do not have major implications on achieving study objectives.

For the NSE indicator, unsatisfactory data/model comparisons are shown mainly at Chau Doc and Tan Chau stations, while at Can Tho NSE is unsatisfactory on very few occasions (2.78\%), and that too during dry months only. While it is possible to improve the NSE values for the two secondary stations by adding nodes and conduits to the simplified model, that will invariably increase the runtime for each simulation, which detracts from the main purpose of this study and will not add any great value to our main objective of developing a model that is able to provide probabilistic estimates of flooding at Can Tho.

Thus, for the purpose of obtaining accurate and fast predictions of flood water levels at Can Tho, the simplified SWMM model performance can be considered good enough.

\subsection{Performance Comparison between the Previous Models and the Simplified SWMM Model for Entire Mekong Delta}

The characteristics and simulation time associated with the process based hydrodynamic models used in previous studies of the Mekong Delta and the simplified SWMM model used here are shown in Table 11.

Table 11. Characteristics and simulation time of different models for the entire Mekong Delta (for a single core on a Intel(R) Core(TM) i5-4210M CPU @ 2.6GHz 2.6GHz processor in a computer with 8.0 GB of memory (RAM)).

\begin{tabular}{ccccc}
\hline \multirow{2}{*}{ No } & \multirow{2}{*}{ Model Name } & \multicolumn{2}{c}{ Number of Nodes and Links } & \multirow{2}{*}{ Simulation Time for one Year(min) } \\
\cline { 3 - 4 } & & Node/Junction & Link/Cross-Section & \\
\hline 1 & ISIS model (1D) & 572 & 3036 & 90 \\
2 & VRSAP model & 1505 & 2111 & - \\
3 & Hydro-GIS model & - & 13,262 & - \\
4 & Detailed SWMM model & 575 & 592 & 10 \\
5 & Simplified SWMM model & 37 & 40 & 1 \\
\hline
\end{tabular}

\section{Conclusions}

In this study we have shown that it is possible to simulate river water levels, with an acceptable level of accuracy (good-excellent), at a location of interest in a complex, deltaic river system like the lower Mekong with a relatively simple (simplified from thousands to several tens of cross sections) and fast (reduction of simulation time from $1.5 \mathrm{~h}$ to around one minute, for a 1 year simulation) numerical model. The simplified model was achieved by iteratively simplifying a complex hydraulic model, with the focus on accuracy of the water levels at a single point of interest (in this case, near Can Tho city).

The overarching objective of developing this simplified and fast model was to subsequently use it for probabilistic flood simulations and for stakeholder based co-design applications. Probabilistic flood modelling involves running thousands of realizations of the model for a given scenario. Even with advanced computer facilities available today, this requirement makes it prohibitive to use some of the 'traditional' models that take hours to run one simulation. Towards this end the simplified SWMM model presented in this article provides a feasible solution. The computing cost is still considerable (e.g., thousand simulations will cost around 17 core-h), but with a modern computer with sixteen cores and adequate amount of memory, such a simulation should be complete within a little more than an hour.

The application of the SWMM, a model developed to simulate drainage/sewerage systems, has been shown to be capable of simulating river systems with complex boundary conditions with the positive results. Additionally, with the advantage of being an open source model and a simple user interface, it would be an appropriate option for multi-stakeholder co-design meeting. Furthermore, the SWMM model also provides a well-documented, clear application programming interface (API) making it possible to embed the model in computer software applications written in a variety of 
computer languages like $\mathrm{C} / \mathrm{C}++$, Fortran and Python. This opens up the possibility of using the resulting model as a basis for innovative applications such as serious-gaming.

The simplification of a model can sometimes lead to degradation of the precision and accuracy of its results. The appropriateness of a simplified model should be looked at in the context of the ultimate intended use of model outcomes. The intended application of the simplified SWMM model for the Mekong delta is two-fold: (a) to derive probabilistic river water level estimates to be used as input for a probabilistic urban flood model; and (b) to be used as a co-design tool in multi-stakeholder environments. In terms of both these utilities, the level of uncertainty associated with the input information is significant. For example, future sea level projections and upstream flow conditions have large uncertainties associated with them (more in latter than in the former). Therefore, striving for high precision modelling output under these realities does not improve the accuracy of the ultimate intended outcomes. In such circumstances, we argue, it is appropriate to sacrifice some accuracy to achieve efficiency and practicality.

Author Contributions: H.N., A.P. and R.R. conceptualized the study. H.N. collated the data, did all the modelling and analysis of results with the guidance of A.P. and R.R. All authors contributed to preparing the manuscript.

Acknowledgments: H.N. is supported by IHE Delft projects OPTIRISK, DURA FR Research fund, and AXA CC\&CR. The authors would like to thank the Mekong River Commission for providing 1-D ISIS model for the entire Mekong Delta. The authors would also like to thank $\mathrm{CH} 2 \mathrm{M}$ company for providing the Flood Modeller Pro licence. R.R. is supported by the AXA Research fund and the Deltares Strategic Research Programme 'Coastal and Offshore Engineering'.

Conflicts of Interest: The authors declare no conflict of interest. The founding sponsors had no role in the design of the study; in the collection, analyses, or interpretation of data; in the writing of the manuscript, and in the decision to publish the results.

\section{References}

1. Small, C.; Nicholls, R.J. A global analysis of human settlement in coastal zones. J. Coast Res. 2003, 19, 584-599.

2. Valiela, I. Global Coastal Change; Blackwell: Oxford, UK, 2006; p. 368.

3. Hallegate, S.; Green, C.; Nicholls, R.J.; Corfee-Morlot, J. Future flood losses in major coastal cities. Nat. Clim Chang. 2013, 3, 802-806. [CrossRef]

4. Hinkel, J.; Nicholls, R.J.; Tol, R.S.J.; Wang, Z.B.; Hamilton, J.M.; Boot, G.; Vafeidis, A.T.; McFadden, L.; Ganopolski, A.; Klein, R.J.T. A global analysis of erosion of sandy beaches and sea-level rise: An application of DIVA. Glob. Planet. Chang. 2013, 111, 150-158. [CrossRef]

5. Ranasinghe, R. Assessing climate change impacts on open sandy coasts: A review. Earth Sci. Rev. 2016, 160, 320-332. [CrossRef]

6. Gorgoglione, A.; Gioia, A.; Iacobellis, V.; Piccinni, A.F.; Ranieri, E. A Rationale for Pollutograph Evaluation in Ungauged Areas, Using Daily Rainfall Patterns: Case Studies of the Apulian Region in Southern Italy. Appl. Environ. Soil Sci. 2016, 2016, 9327614. [CrossRef]

7. Suriya, S.; Mudgal, B.V. Impact of Urbanization on Flooding: The Thirusoolam Sub Watershed-A Case Study. J. Hydrol. 2012, 412-413, 210-219. [CrossRef]

8. Zope, P.E.; Eldho, T.I.; Jothiprakash, V. Impacts of land use-land cover change and urbanization on flooding: A case study of Oshiwara River Basin in Mumbai, India. Catena 2016, 145, 142-154. [CrossRef]

9. Huong, H.T.L.; Pathirana, A. Urbanization and climate change impacts on future urban flooding in Can Tho city, Vietnam. Hydrol. Earth Syst. Sci. 2013, 17, 379-394. [CrossRef]

10. Pathirana, A.; Denekew, H.B.; Veerbeek, W.; Zevenbergen, C.; Banda, A.T. Impact of urban growth-driven landuse change on microclimate and extreme precipitation-A sensitivity study. Atmos. Res. 2014, 138, 59-72. [CrossRef]

11. Domeneghetti, A.; Castellarin, A.; Brath, A. Assessing ratingcurve uncertainty and its effects on hydraulic model calibration. Hydrol. Earth Syst. Sci. 2012, 16, 1191-1202. [CrossRef]

12. Tri, V.P.D.; Trung, N.H.; Tuu, N.T. Flow dynamics in the Long Xuyen Quadrangle under the impacts of full-dyke systems and sea level rise. VNU J. Sci. Earth Sci. 2012, 28, 205-214.

13. Akpo, E.; Crane, T.A.; Vissoh, P.V.; Tossou, R.C. Co-production of knowledge in multi-stakeholder processes: Analyzing joint experimentation as social learning. J. Agric. Educ. Ext. 2015, 21, 369-388. [CrossRef] 
14. Mekong River Commission (MRC). Overview of the Hydrology of the Mekong Basin; Mekong River Commission: Vientiane, Laos, 2005; pp. 73-75, ISSN 17283248.

15. Mekong River Commission (MRC). State of the Basin Report 2010; Mekong River Commission: Vientiane, Laos, 2010; ISBN 9789932080571.

16. Kuenzer, C.; Gue, H.; Huth, J.; Leinenkugel, P.; Li, X.; Cech, S. Flood mapping and flood dynamic of the Mekong Delta: ENVISAT ASAR-WSM base time series analyses. Remote Sens. 2013, 5, 687-715. [CrossRef]

17. Nguyen, H.N. Human Development Report 2007/2008 Flooding in Mekong River Delta, Viet Nam; Human Development Report; United Nations Development Programme: New York, NY, USA, 2008; Volume 4.

18. Balica, S.F.; Dinh, Q.; Popescu, I.; Vo, T.Q.; Pham, D.Q. Flood impact in the Mekong Delta, Vietnam. J. Maps 2014, 10, 257-268. [CrossRef]

19. Nicholls, R.J.; Wong, P.P.; Burkett, V.R.; Codignotto, J.O.; Hay, J.E.; McLean, R.F.; Ragoonaden, S.; Woodroffe, C.D. Coastal systems and low-lying areas. In Climate Change 2007: Impacts, Adaptation and Vulnerability, Contribution of Working Group II to the Fourth Assessment Report of the Intergovernmental Panel on Climate Change; Cambridge University Press: Cambridge, UK, 2007.

20. Wong, P.-P.; Losada, I.J.; Gattuso, J.P.; Hinkel, J.; Khattabi, A.; McInnes, K.L.; Saito, Y.; Sallenger, A. Coastal Systems and Low-Lying Areas. In Climate Change 2014: Impacts, Adaptation, and Vulnerability. Part A: Global and Sectoral Aspects; Contribution of Working Group II to the Fifth Assessment Report of the Intergovernmental Panel on Climate Change; Cambridge University Press: Cambridge, UK; New York, NY, USA, 2014.

21. Hapuarachchi, H.A.P.; Takeuchi, K.; Zhou, M.C.; Kiem, A.S.; Georgievski, M.; Magome, J.; Ishidaira, H. Investigation of the Mekong River basin hydrology for 1980-2000 using the YhyM. Hydrol. Process. 2008, 22, 1246-1256. [CrossRef]

22. Kingston, D.G.; Thompson, J.R.; Kite, G. Uncertainty in climate change projections of discharge for the Mekong River Basin. Hydrol. Earth Syst. Sci. 2011, 15, 1459-1471. [CrossRef]

23. Eastham, J.; Mpelasoka, F.; Ticehurst, C.; Dyce, P.; Ali, R.; Kirby, M. Mekong River Basin Water Resources Assessment: Impacts of Climate Change. In CSIRO Water for a Healthy Country National Research Flagship Report; CSIRO: Canberra, Australia, 2008; Volume 153, ISSN 1835-095X.

24. Hoanh, C.T.; Jirayoot, K.; Lacomne, G.; Srunetr, V. Impacts of Climate Change and Development on Mekong Flow Regimes First Assessment-2009; MRC Management Information Booklet Series No. 4; Mekong River Commission: Vientiane, Laos, 2011; Volume 16.

25. Västilä, K.; Kummu, M.; Sangmanee, C.; Chinvanno, S. Modelling climate change impacts on the flood pulse in the lower Mekong floodplains. J. Water Clim. Chang. 2010, 1, 67-86. [CrossRef]

26. Räsänen, T.A.; Koponen, J.; Lauri, H.; Kummu, M. Downstream hydrological impacts of hydropower development in the Upper Mekong Basin. Water Resour. Manag. 2012, 26, 3495-3513. [CrossRef]

27. Räsänen, T.A.; Someth, P.; Lauri, H.; Koponen, J.; Sarkkula, J.; Kummu, M. Observed river discharge changes due to hydropower operations in the Upper Mekong Basin. J. Hydrol. 2017, 545, 28-41. [CrossRef]

28. Tran, P.; Marincioni, F.; Shaw, R.; Sarti, M.; Van An, L. Flood risk management in Central Viet Nam: Challenges and potentials. Nat. Hazards 2008, 46, 119-138. [CrossRef]

29. Hoang, L.P.; Biesbroek, R.; Tri, V.P.D.; Kummu, M.; van Vliet, M.T.H.; Leemans, R.; Kabat, P.; Ludwig, F. Managing flood risks in the Mekong Delta: How to address emerging challenges under climate change and socioeconomic developments. Ambio 2018, 1-15. [CrossRef] [PubMed]

30. Wassmann, R.; Hien, N.X.; Hoanh, C.T.; Tuong, T.P. Sea level rise affecting the Vietnamese Mekong Delta: Water elevation in the flood season and implications for rice production. Clim. Chang. 2004, 66, 89-107. [CrossRef]

31. Royal HaskoningDHV; WUR; Deltares; Rebel. Mekong Delta Plan: Long-Term Vision and Strategy for a Safe, Prosperous and Sustainable Delta; Prepared under the Strategic Partnership Arrangement on Climate Change Adaptation and Water Management between the Netherlands and Vietnam: Hanoi, Vietnam; Amersfoort, The Netherlands, 2013; p. 126.

32. National Institute for Urban and Rural Planning (NIURP) under Vietnam Ministry of Construction. Development Strategies (CDS) for Medium-Size Cities in Vietnam: Can Tho and Ha Long; Vietnam Ministry of Construction: Hanoi, Vietnam, 2010.

33. CCCO \& ISET. Peri-Urban Development Planning and Flooding Problems: Story of New Urban Areas in Can Tho City, Viet Nam; ISET: Hanoi, Vietnam, 2015. 
34. Lauri, H.; De Moel, H.; Ward, P.J.; Räsänen, T.A.; Keskinen, M.; Kummu, M. Future changes in Mekong River hydrology: Impact of climate change and reservoir operation on discharge. Hydrol. Earth Syst. Sci. 2012, 16, 4603-4619. [CrossRef]

35. Piman, T.; Lennaerts, T.; Southalack, P. Assessment of hydrological changes in the lower Mekong basin from basin-wide development scenarios. Hydrol. Process. 2013, 27, 2115-2125. [CrossRef]

36. Pokhrel, Y.; Burbano, M.; Roush, J.; Kang, H.; Sridhar, V.; Hyndman, D. A Review of the Integrated Effects of Changing Climate, Land Use, and Dams on Mekong River Hydrology. Water 2018, 10, 266. [CrossRef]

37. Le, T.V.H.; Nguyen, H.N.; Wolanski, E.J.; Tran, T.C.; Haruyama, S. The combined impact on the flooding in Vietnam's Mekong River delta of local man-made structures, sea level rise, and dams upstream in the river catchment. Estuarine Coastal. Estuar. Coast. Shelf Sci. 2007, 71, 110-116. [CrossRef]

38. Le, T.V.H.; Haruyama, S.; Nguyen, H.N.; Tran, T.C. Study of 2001 Flood Using Numerical Model in the Mekong River Delta, Vietnam. In Proceedings of the International Symposium on Floods in Coastal Cities under Climate Change Conditions, Khlong Nueng, Thailand, 23-25 June 2005; pp. 65-73.

39. Van, P.D.T.; Popescu, I.; Van Griensven, A.; Solomatine, D.P.; Trung, N.H.; Green, A. A study of the climate change impacts on fluvial flood propagation in the Vietnamese Mekong Delta. Hydrol. Earth Syst. Sci. 2012, 16, 4637-4649. [CrossRef]

40. Rossman, L.A. Storm Water Management Model User's Manual; EPA: Cincinnati, OH, USA, 2015; pp. 1-353.

41. Pathirana, A. SWMM5-EA-A tool for learning optimization of urban drainage and sewerage systems with genetic algorithms. In Proceedings of the 11th International Conference on Hydroinformatics, New York, NY, USA, 17-21 August 2014; CUNY Academic Works: New York, NY, USA, 2014.

42. Nash, J.E.; Sutcliffe, J.V. River flow forecasting through conceptual models: Part 1. A discussion of principles. J. Hydrol. 1970, 10, 282-290. [CrossRef]

43. Sutherland, J.; Walstra, D.J.R.; Chesher, T.J.; van Rijn, L.C.; Southgate, H.N. Evaluation of coastal area modelling systems at an estuary mouth. Coast. Eng. 2004, 51, 119-142. [CrossRef]

(C) 2018 by the authors. Licensee MDPI, Basel, Switzerland. This article is an open access article distributed under the terms and conditions of the Creative Commons Attribution (CC BY) license (http:/ / creativecommons.org/licenses/by/4.0/). 